Descargo de responsabilidad: las opiniones expresadas en los manuscritos son responsabilidad exclusiva de los autores. No necesariamente reflejan las opiniones de la editorial ni la de sus miembros.

\title{
La prisión preventiva como medida de inocuización en el derecho penal del enemigo
}

\section{The preventive prison as a measure of inoculation in the criminal law of the enemy}

Recibido: $12 / 10 / 2021$

Publicado: 20/01/2022

\author{
Héctor Geovany Loyo Castañeda \\ Universidad San Carlos de Guatemala \\ lic.gc@hotmail.com \\ https://orcid.org/0000-0002-9422-8166
}

\section{Referencia}

Loyo Castañeda, H. G. (2022). La prisión preventiva como medida de inocuización en el derecho penal del enemigo. Revista Académica Sociedad Del Conocimiento Cunzac, 2(1), 81-87. DOI: https://doi.org/10.46780/sociedadcunzac.v2i1.16

\section{Resumen}

OBJETIVO: resaltar la importancia de los convenios internacionales en materia de derechos humanos, en especial los derechos del sindicado al estar privado de su libertad por ser considerado enemigo público. MÉTODO: se utilizó el método inductivo, partiendo de una noción particular para derivar conclusiones que se complementa con el método deductivo para encontrar conclusiones validas de lo que es la prisión preventiva actual como medida de inocuización por sur una amenaza. RESULTADOS: no resulta adecuado a los estándares constitucionales y convencionales la aplicación de la prisión preventiva como un mecanismo de inocuización al sindicado considerado enemigo ya que no se pondera de manera objetiva su derecho de libertad. CONCLUSIÓN: Ios jueces y magistrados al momento de ponderar en sus resoluciones se aplica la prisión preventiva como una medida de inocuización al sindicado por considerarlo un enemigo público.

\section{Palabras clave}

prisión preventiva, inocuización, derecho penal del enemigo

\section{Abstract}

OBJECTIVE: the purpose of this essay is to highlight the importance of international conventions on human rights, especially the rights of the accused when he is deprived of his liberty because he is considered a public enemy. METHOD: to develop the subject of preventive detention as a measure of Inoculation, the inductive method was used, starting from a particular notion to derive conclusions that is complemented by the deductive method to find valid conclusions of what is the current preventive detention as a measure of Inoculation by South a threat. RESULTS: it is not adequate to the constitutional and conventional standards the application of preventive detention as a mechanism of Inocuation to the accused considered enemy since their right to freedom is not objectively 
weighed. CONCLUSION: that the judges and magistrates at the time of 'weighing in their resolutions, preventive detention is applied as a measure of innocuousness to the accused because they consider him a public enemy.

\section{Keywords}

preventive prison, inoculation, criminal law of the enemy

\section{Introducción}

Guatemala como un Estado parte en los convenios internacionales, y en la practica el Organismo Judicial, por medio de sus Jueces, Magistrados deben de tomar en cuenta la convencionalidad en resoluciones basadas en tratados internacionales en relación a los Derechos Humanos de las personas en especial a los privados de libertad ya que tienen relación con procesos penales en cuanto a la medida de coerción como lo es la prisión preventiva aplicada a las personas de manera desproporcional, considerándose una medida de inocuización por representar un peligro a la sociedad.

Por ello el problema de la investigación se planteó con la interrogante cresulta adecuado a los estándares constitucionales y convencionales la aplicación de la prisión preventiva como un mecanismo de inocuización al sindicado al ponderar su derecho a la libertad contra los hechos cometidos y sus efectos cuando se trata de un enemigo público? por lo cual se establece la hipótesis planteada "No resulta adecuado a los estándares constitucionales y convencionales la aplicación de la prisión preventiva como un mecanismo de inocuización al sindicado al ponderar su derecho a la libertad contra los hechos cometidos y sus efectos cuando se trata de un enemigo público, esto debido a que el sistema jurídico guatemalteco se sustenta en la supremacía de la Constitución Política de la República y los tratados internacionales de derechos humanos, donde ambos instrumentos jurídicos desarrollan un catálogo de derechos fundamentales y garantías procesales que deben de ser de aplicación obligatoria en el sistema de justicia, pero que en ocasiones el Estado se ve impulsado a separarse de los estándares constitucionales y convencionales cuando se persigue a un enemigo público, inclusive desde la aplicación de la prisión preventiva dentro del proceso penal como un mecanismo de inocuización al sindicado al ponderar su derecho a la libertad contra los hechos cometidos y sus efectos en la víctima y la sociedad en general"

\section{Contenido}

\section{Derecho penal del enemigo}

Existe una problemática actual que implica la participación del Estado con la realidad delictiva que vivimos, con la formación de grupos delincuencias y la prevención del delito que se convierte en una política de Estado, sin tener una efectividad latente en la sociedad moderna, tecnológica, con influencias y corrupta a la que actualmente se ve reflejado por el gran índice de delincuencia que afecta a una sociedad no importando su estatus social, religioso, económico, cultural. 
Por la problemática actual en el gran índice de delincuentes modernos, la sobrepoblación en los centros carcelarios, se busca crear nuevos métodos con duras penas con el fin de disminuir los hechos delictivos que sufre una sociedad sin tener buenos resultados ya que es una problemática que el Estado ha sido incapaz de disminuir el problema social delincuencial y esto se ve reflejado en las estadísticas.

Para Jakobs \& Calcio (2003) el individuo que no admite ser obligado a entrar a un estado de ciudadanía no puede participar de los beneficios del concepto de persona." (p. 40); la neutralización de ciertos sujetos se ve necesaria que por sus crímenes ellos mismos se han excluido de la sociedad y del Estado de Derecho, por lo que no pueden ejercer los mismos derechos que a otros ciudadanos se les garantiza dentro del proceso penal.

En la actualidad esta teoría ha tomado fuerza en los últimos veinte años, por los actos terroristas cometidos en Estados Unidos de América en el año 2001, con las torres gemelas, pero la historia nos enseña que existieron otros grupos terroristas que causaron terror a una sociedad, un caso no muy viejo se dio en Colombia en los años de 1980, grupos de narcotráfico que doblegaron a un país y el grupo denominado FARC. Pero no solo un grupo son considerados enemigos públicos, existen personas individuales como los que cometen actos ilícitos sexuales como los violadores de niños, adolescentes, mujeres, ellos son considerados enemigos públicos por el mal que causan a sus víctimas.

\section{Derecho garantista}

El proceso penal también es un derecho garantista ya que en la actualidad existen principios fundamentales de carácter penal y procesal que velan por las personas sindicadas de un hecho delictivo, limitando la capacidad del Estado y al órgano de justicia al momento de una investigación penal y en el desarrollo de un proceso penal.

Según Ferrusola (2006), citado por el Instituto de Investigaciones Jurídicas de la UNAM. Garantizar en el proceso penal que todas las partes gocen de poder impulsar, invocar los derechos garantistas de carácter humano, legal que tengan como fin principal la dignidad humana, todo proceso penal goza de garantías que enriquecen el proceso penal, esto en virtud que la parte que se ve afectada puedo invocarla ante él juzgador.

Entre los principios fundamentales rectorares y denominados axiológicos del derecho penal que tienen relevancia dentro de un proceso penal son: legalidad, defensa, proporcionalidad, humanista, eficacia. Como referencia el principio de legalidad que bien lo encontramos en el artículo 17 de la Constitución Política de la República de Guatemala que dice " No son punibles las acciones u omisiones que no estén calificadas como delito o falta y penadas por ley........." mismo fundamento lo encontraos en el artículo 1 del Código Procesal Penal que dice. "No hay pena sin ley. (Nullum poena sine lege) No se impondrá penal alguna si la ley no lo hubiese fijado con anterioridad". 
Los principios axiológicos velan a favor de la persona que es sindicado de un hecho delictivo poniendo un límite a la intervención del Estado y los juzgadores al momento de tomar una decisión en resolución o sentencia ya que estos principios están sujetos a los derechos fundamentales de las personas.

\subsection{Derechos humanos}

Los derechos humanos tomaron fuerza después de la primera guerra mundial ya que por la violación a los derechos humanos, por la desmedida fuerza y por no valorar la vida de las personas poco a poco los Estados de América latina y en Europa comenzaron a fortalecer leyes en las cuales incorporaban a sus legislaciones derechos fundamentales y de manera general los derechos humanos de las personas fueron década a década tomando relevancia tanto nacionalmente como internacionalmente, creando tratados internacionales en los cuales serviría para los Estados partes poner en práctica dentro de un proceso penal dichos derechos fundamentales, guardando la vida, respetando la dignidad humana no importando la religión, la cultura, la etnia, estatus económico etc.

Derechos humanos de primera generación. Como se ha expuesto, ciertos acontecimientos dieron lugar a la primera generación de derechos humanos, Salazar (1989), explica que la Declaración de los Derechos Humanos, por el acontecimiento histórico de la Declaración de Independencia de los Estados Unidos, del 4 de julio de 1776, donde por primera vez se habla, de manera oficial los derechos humanos de las personas.

Dentro de la Constitución Política de la República de Guatemala, estos derechos de primera generación, segunda generación se encuentra desarrollados dentro del capítulo I del Título II relativo a los derechos individuales como el derecho a la vida, igualdad, libertad de acción, derechos de carácter procesal, de libre pensamiento, de locomoción, de manifestación, de propiedad, de acceso a los tribunales de justicia, entre otros.

El Pacto Internacional de Derechos Económicos, Sociales y Culturales del año 1966) indican Estos derechos humanos buscan concretarse dentro de una justa y realidad social, los cuales son desarrollados en el capítulo II del Título II de la Constitución Política de la República, que hacen referencia a los derechos sociales como la familia, la cultura, lo relativo a las comunidades indígenas, educación, deporte, salud, seguridad, asistencia social y el trabajo.

\section{Centros Penitenciarios}

Los centros penitenciarios o como coloquialmente se les llama cárceles en Guatemala, en la actualidad están a cargo del Ministerio de Gobernación, pero en la actualidad existe una sobrepoblación en dichos lugares, sin tener un control absoluto en dichos lugares, ya que dentro de los centros preventivos, cárceles de máxima seguridad se da en la realidad un gobierno interno controlado por reclusos de altas peligrosidad y grupos como maras, quienes tienen el control ante las autoridades encargadas de la rehabilitación de la conducta delictiva de estas personas. 


\section{Inocuización}

La inocuización es parte de esta teoría en el derecho penal actual, la cual a través de una política de criminalización pretende reducir las capacidades delictivas de un enemigo público, aplicado regularmente en la ejecución de la pena.

Von Liszt, citado por Pérez (2007) Explica el jurista Alemán que: "Existen tres tipos de criminales, los que requieren corrección, los que no necesitan de corrección y los que deben neutralizarse por no ser susceptibles a corrección." (p. 1 12). El tercer tipo de criminales según Von (2007), citado en el párrafo anterior, se considera incorregible, por lo tanto, amerita un tratamiento distinto determinado por su peligrosidad, debiéndose de separar permanentemente de la sociedad neutralizándolo no solamente a través de la pena como sanción final sino desde que es detenido para imputarle los delitos en que ha incurrido a través de la prisión preventiva, esta práctica ya se ve en los delitos de alto impacto social que son conocidos por la población, donde la aplicación de la prisión preventiva se ha vuelto una primicia para no dejar en libertad a un enemigo público altamente peligroso (p. 112).

Con los antecedentes históricos de la pena incluyendo la detención de presuntos delincuentes en tiempos antiguos, es evidente la progresiva participación de idealistas elaborando teorías que pretendieran minimizar la intervención excesiva del Estado a través de su sistema de justicia penal.

Los tratados internacionales, los convenios internacionales son normas que los Estados partes deben de tomar en cuenta en el ámbito jurídico, legal y en derechos humanos, ya que existe una gran gama de tipos penales que anticipan o son parte de los problemas sociales actuales en cuanto a la criminalidad y las conductas de sujetos que son considerados un peligro para el Estado, para las sociedades y para proteger los bienes jurídicos tutelados, un ejemplo de esto son los casos de terroristas que en Asía, Europa, América la población ha resultado víctima de las practicas desmedidas por grupos extremistas.

Ante la jurisprudencia convencional relativa a la prisión preventiva como medio de inocuización dentro del proceso penal, cabe señalar que los jueces ordinarios, dentro de un control difuso constitucional, tendrían que fundamentar sus resoluciones judiciales en base a lo dispuesto por la Corte Interamericana, no aplicando esta medida de coerción o dejando en libertad a la persona después de cumplidos los plazos legales en que debería de durar la prisión preventiva, pero en la realidad los jueces no aplican la convencionalidad debido a la marcada postura de fundamentar sus sentencias apegadas a lo que regula la ley.

Una opinión emitida por la Comisión Interamericana (2010) caso Cabrera García y Montiel Flores Vs. México citada anteriormente resuelve que (...) así donde todos los jueces tienen competencia para dejar de aplicar una ley al caso concreto por contravenir la Constitución nacional, el grado de control de convencionalidad resulta de mayor alcance, al tener todos los jueces nacionales la atribución de inaplicar la norma convencional (p. 26). 


\section{Conclusión}

Efectivamente en Guatemala como en muchos países de América latina la prisión preventiva se convirtió en la actualidad una medida de inocuización, para un infractor de una norma legal sujeto a una investigación que goza de principios irrenunciables que envisten el proceso penal moderno como lo son: el principio de inocencia, toda duda favorece al reo, legalidad, proporcionalidad entre muchos que sustenta el derecho penal, y es inevitable esconder que en los centros carcelarios la aglomeración de personas es desmesurada violando derechos de toda persona humana por las condiciones en las que viven ya que el Estado es incapaz de cumplir los objetivos de rehabilitación, reeducación a estas personas que en ningún momento dejan de perder su calidad de ciudadanos.

No resulta adecuado a los estándares constitucionales y convencionales la aplicación de la prisión preventiva como un mecanismo de inocuización al sindicado ya que al ponderar su derecho a la libertad contra un hecho tipificado como delito es tratado un enemigo público, esto debido a que el sistema jurídico guatemalteco se sustenta en la supremacía de la Constitución Política de la República y los tratados internacionales de derechos humanos, donde ambos instrumentos jurídicos desarrollan un catálogo de derechos fundamentales y garantías procesales que deben de ser de aplicación obligatoria en el sistema de justicia.

\section{Referencias}

Codigo Procesal Penal Guatemalteco. Decreto 17-73. (1973), Congreso de la República de Guatemala.

Constitucion Politica de la Republica de Guatemala. (1985). Asamblea Nacional Cosntituyente. Jakobs, G \& Cancio, M (2003).Derecho penal del enemigo. Madrid: Civitas.

Instituto de Investigacion Juridicas Garantismo Penal. Luigi Ferrajoli. México, D F. UNAM. 2006.

Salazar, Carlos (1989). Derechos Humanos. Antecedentes y Protecciones en el Cuadragésimo Aniversario de la Carta de la ONU San José . Universidad de Costa Rica

Pacto Internacional de Derechos Economicos Sociles y Culturales (1966).

Perez, J. (2007). Archivos de Criminologia, Criminalisticay Seguridad Privada. España: Dialned.

\section{Sobre el autor}

El autor del presente ensayo es graduado de Licenciado en Ciencias Jurídicas y Sociales en el año 2011, actualmente es estudiante de la Maestría de Derecho Procesal Penal en la Universidad San Carlos de Guatemala. 


\section{Financiamiento de la investigación}

Con recursos propios de los investigadores

\section{Declaración de intereses}

Declaran no tener ningún conflicto de intereses, que puedan haber influido en los resultados obtenidos o las interpretaciones propuestas.

\section{Declaración de consentimiento informado}

El estudio se realizó respetando el Código de ética y buenas prácticas editoriales de publicación.

\section{Derechos de uso}

Copyright@ 2022 por Héctor Geovany Loyo Castañeda

Este texto está protegido por una licencia Creative Commons 4.0

Este texto está protegido por la Licencia Creative Commons Atribución 4.0 Internacional.

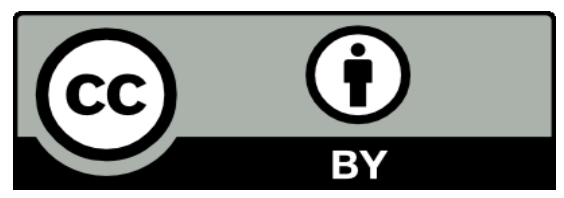

Este texto está protegido por una licencia

Creative Commons 4.0.

Es libre para compartir, copiar y redistribuir el material en cualquier medio o formato y adaptar el documento, remezclar, transformar y crear a partir del material para cualquier propósito, incluso comercialmente, siempre que cumpla la condición de atribución: debe reconocer el crédito de una obra de manera adecuada, proporcionar un enlace a la licencia, e indicar si se han realizado cambios. Puede hacerlo en cualquier forma razonable, pero no de forma tal que sugiera que tiene el apoyo del licenciante o lo recibe por el uso que hace. 